\title{
Economies of Scale: Research-Driven Social Impact in the Housing Studio
}

SHARON HAAR, FAIA, Professor and Chair

University of Michigan

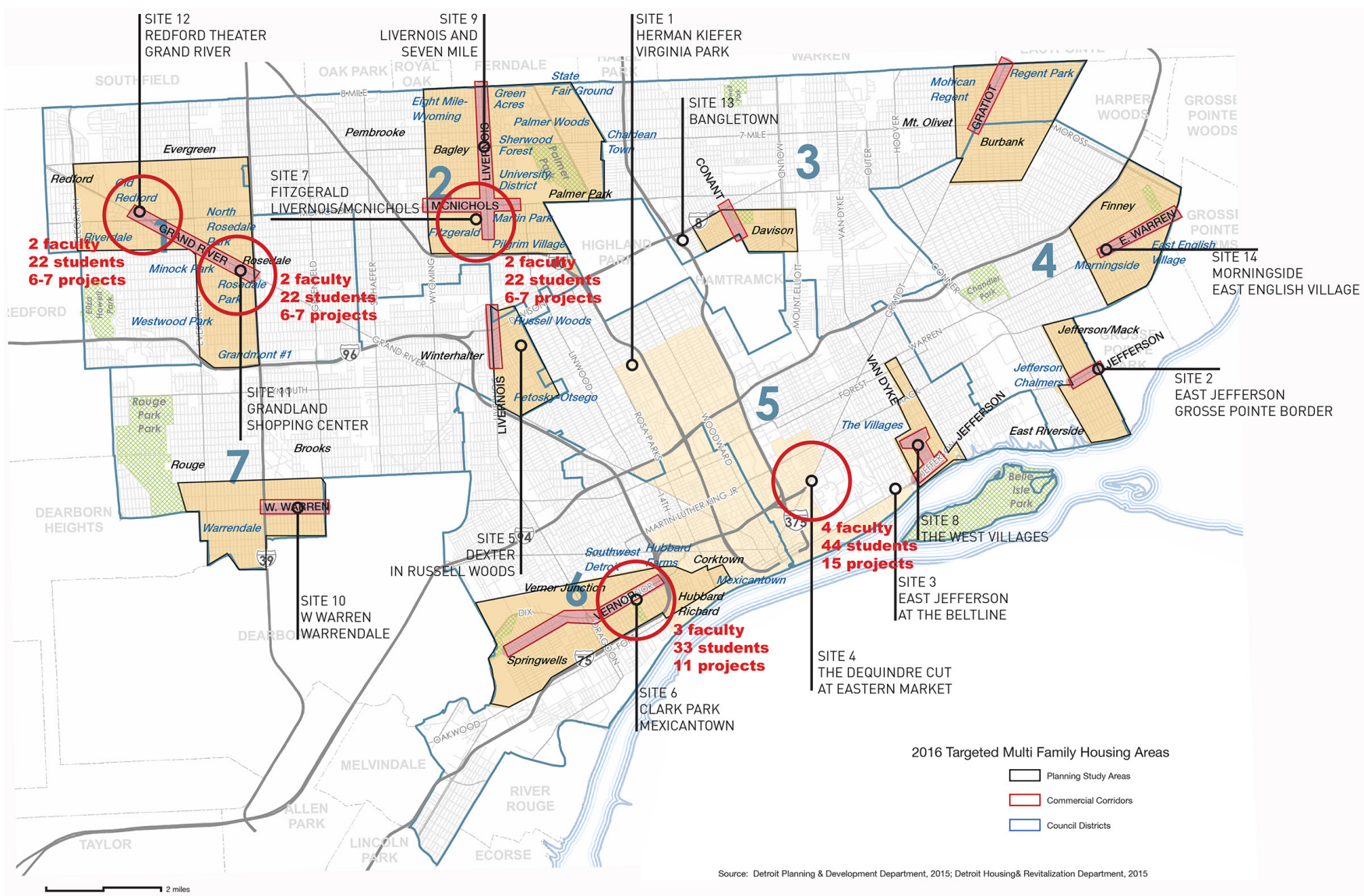

Figure 1. Relationship of Fall 2016 studio projects to Detroit's multi-family housing target areas and commercial corridor development. (Credit: Lars Gräbner)

\section{INTRODUCTION}

How do we engage and envision "bottom-up" social change in the context of the academic design studio? What does it look like, and how is it taught? This paper shares a novel research-based studio engaged with large-scale projects in the city of Detroit that diverges from the small-scale, often design-build projects most often undertaken in communitybased practice in the academy. Framed by the context of a research-intensive academic institution-the University of Michigan-the pedagogy asks how can we educate students in the potential for social impact and capacity-building at scale? In parallel, how can we leverage the research capacities of a large student body to advance the study of affordable housing and neighborhood development in the context of a city such as Detroit?

Since 2016, the integrated housing studios at Taubman College at University of Michigan have been committed to projects chosen and driven by the Detroit Planning and Development Department (PDD). Each fall, over forty teams of students work in studios that look at multiple sites in the city slated for development in the near-term, testing urban design, program, building technology, and community capacity building through speculative, yet "client" driven work. Given 


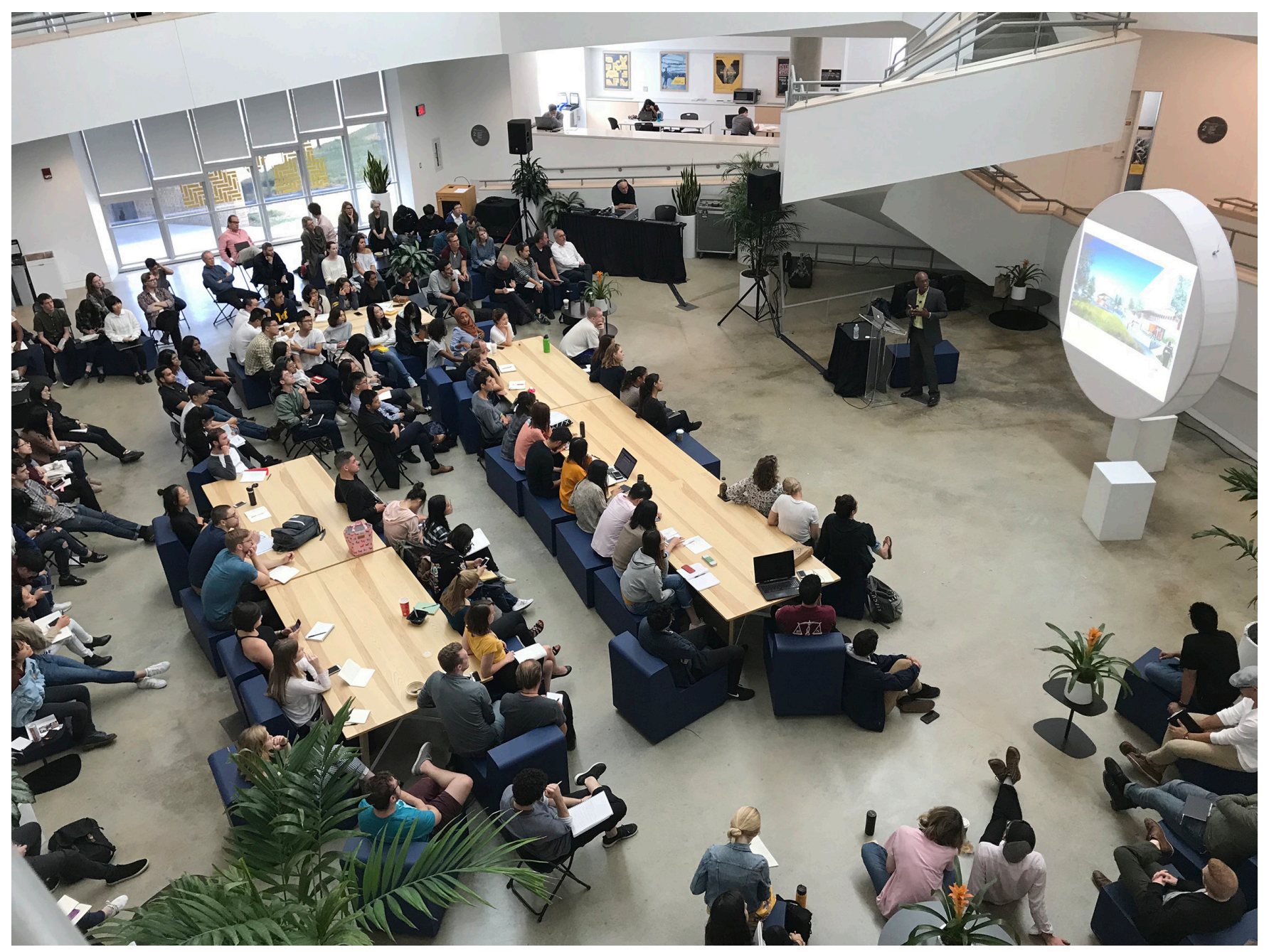

Figure 2. Maurice Cox presenting Detroit Planning and Development Department initiatives to Systems Studio students in the Taubman College Commons, Fall 2018. (Credit: Sharon Haar)

the rapid pace of development in the city, the research capacities of the institution, its faculty, and its students allow the directors and project managers of the PDD to test site scenarios before releasing RFPs to architect-developer teams. While not strictly "participatory"-although the students do extensive on-site research and often meet with community organizations and constituencies-the purpose of the studio is to leverage student research while exposing them to the real-world tensions between community needs and developer-driven housing production. Through iterative reviews and interactions with the PDD, students are required to work within market-driven constraints, while maximizing opportunities to rethink domestic arrangements, the economics of home ownership, and the potentials of new building technologies. The long-term "social impact" of such work is in the recognition of the agency of the architect to question contemporary models of housing development, the inevitability of gentrification, and normative social and urban configurations. The primary goal of the collaboration is to spark innovation among prospective developers with outsidethe-box design approaches that demonstrate how housing could contribute to the social and economic restructuring process of the city, while also contributing to the culture of design. The student concepts are intended to start a discourse of what inclusive housing can look like for future generations of Detroiters, how changing lifestyles can be sustainably integrated in new neighborhood developments, and how innovative development in Detroit can serve as an inspiration for other American cities.

\section{DETROIT}

Detroit's 139 square-land mass was built out as a residential fabric of largely single-family homes intersected by the diagonal streets emanating from downtown and crisscrossed by miles of linear industrial corridors that formed the basis of the regional automotive industry. As Dan Pitera has demonstrated, the combined cities of Boston and San Francisco, plus the island of Manhattan (together amounting to 118 square miles and 

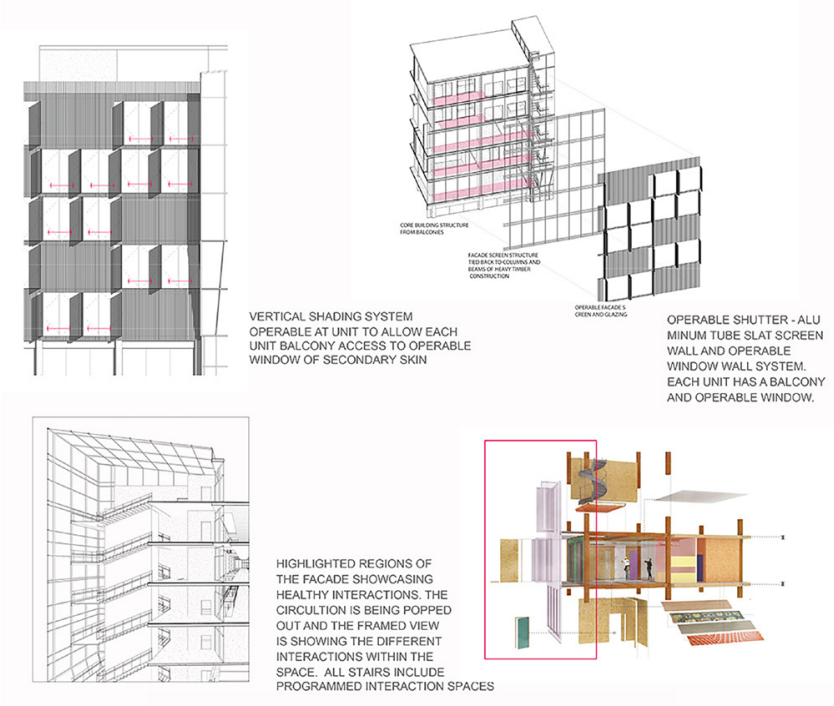

Figure 3. Flex Flats, excerpt from Integrated Building Systems submission illustrating façade study. Siobahn Klinkenberg, Patrick Linder, Liz Szatko, Tyler Whitney; faculty Kim Dowdell and U. Sean Vance, Fall 2016.

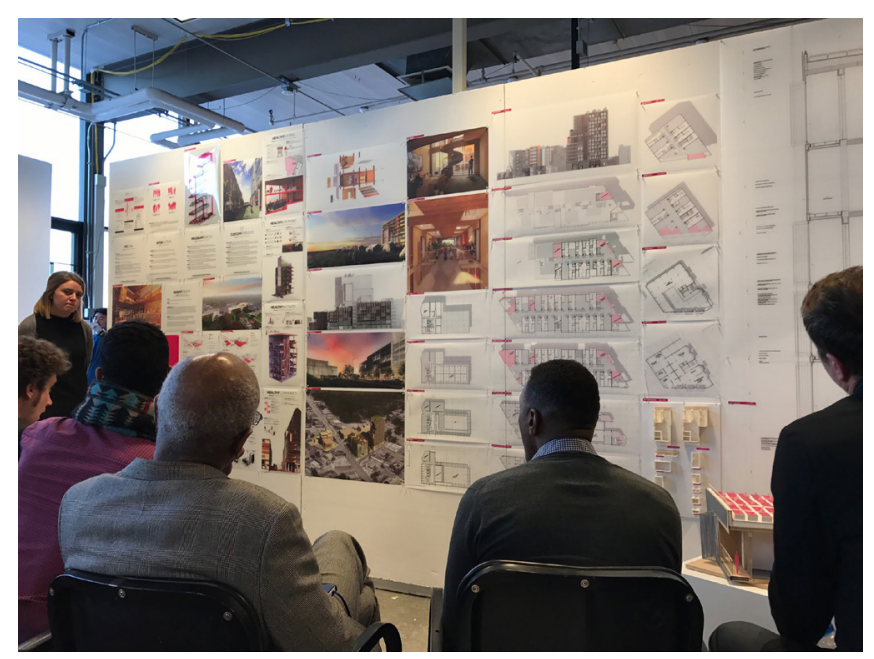

Figure 4. Systems Studio Final Review, Flex Flats (Siobahn Klinkenberg, Patrick Linder, Liz Szatko, Tyler Whitney; faculty Kim Dowdell and U. Sean Vance), Taubman College, Fall 2016. (Credit: Sharon Haar)

containing over 3 million residents) can be readily arranged to fit within Detroit's borders. While experiencing a modest increase in population over the past several years, Detroit has lost $60 \%$ of its population since its peak of 1.8 million in 1950 , which has resulted in a massive redistribution of population and wealth from the city to its region. What does this look like on the ground? Pitera observes:

...a neighborhood's density that consists of mostly, if not entirely of individual houses lacks the portfolio diversity needed to withstand small changes. For example, if four families leave an apartment or condominium block, the overall [urban] living experience may still feel dense. ...if four families leave a block of detached housing it may begin to appear that something is going wrong in the neighborhood. This block type has a harder time self-correcting and may even accelerate the abandonment process.

Additionally, despite the city's vast territory and population decline, it does not have an overabundance of housing stock. Abandonment left many properties in disrepair, much beyond hope of revival. There is a lack of affordable, quality housing. Extremely low-density housing makes neighborhoods unwalkable, hard to reach by the city's limited mass transit system, difficult to service, and devoid of retail and other services. Consequently, the Detroit Planning and Development Department, under the leadership of former director Maurice Cox, has been utilizing two strategies for urban redevelopment:

- To target development along significant urban corridors, building up what Cox refers to as "missing middle" medium density housing and mixed-use development.

- To develop a strategy of major landscape propositions in support of this new development.

The majority of this work avoids the greater downtown area, which is the current focus of the "revival" of Detroit covered in the national news and is driven by big investors such as Dan Gilbert of Quicken Loans and the Illitch family, owners of among other entities, Little Caesars Pizza, the Detroit Red Wings and Tigers, and the Motor City Casino. Instead, the PDD's work is within the communities that have stayed through the city's decline, bankruptcy, and resurgence, a population that is overwhelmingly African-American. The work of the Taubman College studio takes up the first strategy, utilizing sites in the city's designated development areas and briefs designed to produce medium-density residential projects (Figure 1).

\section{COMMON GOALS OF THE SYSTEMS STUDIO}

For the Taubman College students, all of whom are in the final year of their professional, Master of Architecture degree, the Detroit-focused Systems Studio offers an opportunity to engage public discourse around contemporary housing and neighborhood issues while working on "real" projects and sites slated for imminent development by both non-profit and for-profit developers. Their iterative research receives feedback from the city's planning director, PDD staff, outside experts, and potential clients at multiple contact moments, including midterm and final reviews. At the same time, they are encouraged to develop new and innovative housing concepts that can be tested outside of the academic realm. The overlap with a technology-intensive lecture class provides content and a feedback loop for exploration of sustainability from the scale 


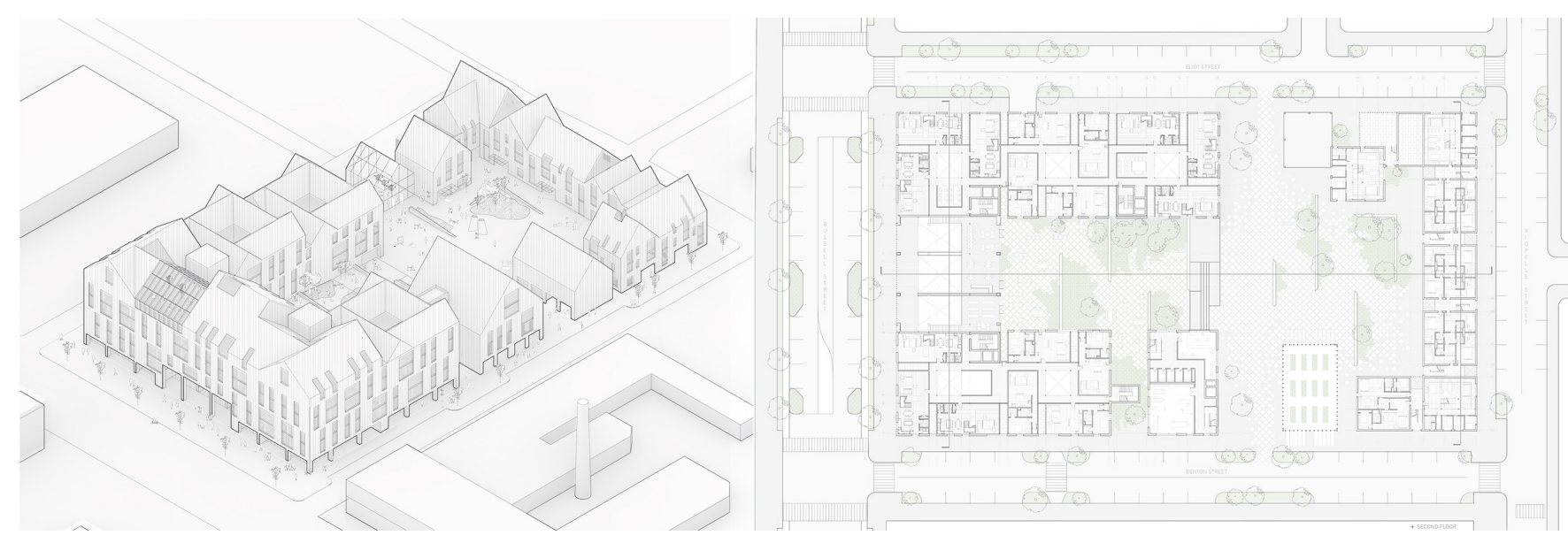

Figure 5. Russel Creative: A Live + Work Collective (Sarah Arthur, Brian Baksa, and Eric Minton; faculty Kathy Velikov and Jonathon Rule), Taubman College, Fall 2018.

of the neighborhood to the performance of the building. Finally, as they see components of their schematic designs taken up by developers and architects, they begin to understand the potential of their work to create social impact (Figure 2).

Similarly, the Detroit Planning and Development Department is able to formulate specific research topics or questions that they would like taken up on select sites where studies of housing typologies and innovative solutions to building and structural technologies, program mix, and new domestic arrangements might be valuable to the informing of alternatives to off-the-shelf development pro forma. The student teams' ability to iterate multiple strategies can offer new insights on site specific qualities and values, informing efforts to, for instance, the development of form-based codes or prototypical solutions that can be applied on multiple sites. Because the students' work informs the writing of Requests for Proposals, their efforts do not replace the work of professional architects. Rather, they expand the capacities of a lean city department, while challenging the community of developers and their architects to recognize the value of innovative design.

\section{STUDIO WORK}

During the semester-long studio, student teams from ten or more studios develop design proposals for housing sites selected from the Detroit Planning Department master list. Each studio is focused on a specific design challenge such as senior living, multi-generational housing, live-work environments, healthy living, or cooperative housing. The student teams create a comprehensive urban and building strategy for each site, from initial analysis to early-phase design development. The studio is aligned with an integrative building systems class taught by a team consisting of an architect, structural engineer, and mechanical engineer, which requires the students to consider their projects in the larger context of urban and building sustainability and constructability. In

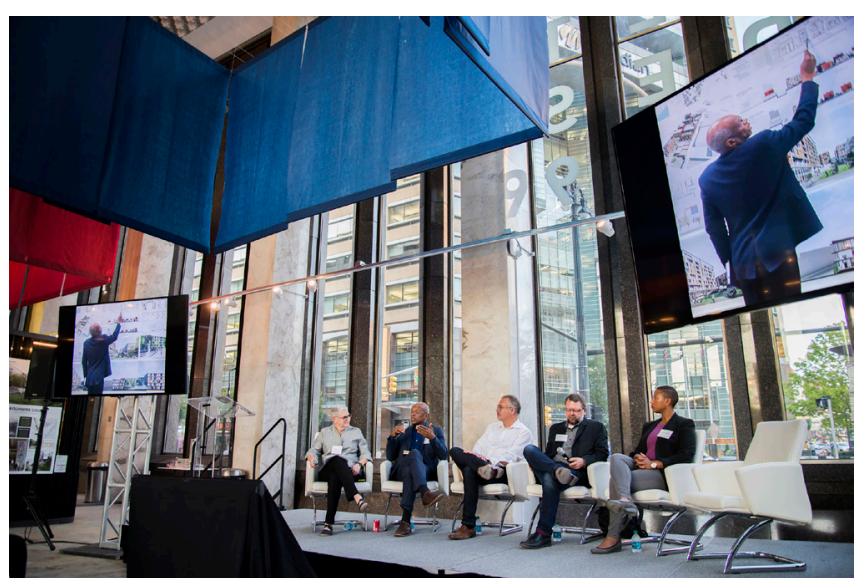

Figure 6. Taubman College sponsored panel at Detroit Design 139 in 2017. From left to right Sharon Haar, former Chair of the Architecture Program; Maurice Cox, former Director of Detroit PDD; Lars Gräbner, Systems Studio Coordinator; and Craig Borum and Kimberly Dowdell, faculty who have taught in the studio. (Credit: Taubman College)

addition to their final project presentation, each student team of three produces a comprehensive package demonstrating their approach to relevant zoning and building codes, program, water management, life-cycle costing, structural and mechanical systems, outline specifications, orientation and daylighting, building materials, wall sections, and neighborhood/site strategy (Figure 3).

Here, two studio projects serve as examples of the myriad projects undertaken over the past three years.

Flex Flats, a project that took on multi-generational housing, put emphasis on an overall strategy of accessibility and the ability to age in place. The site strategy suggested the ability to undertake phased construction using modular components, 


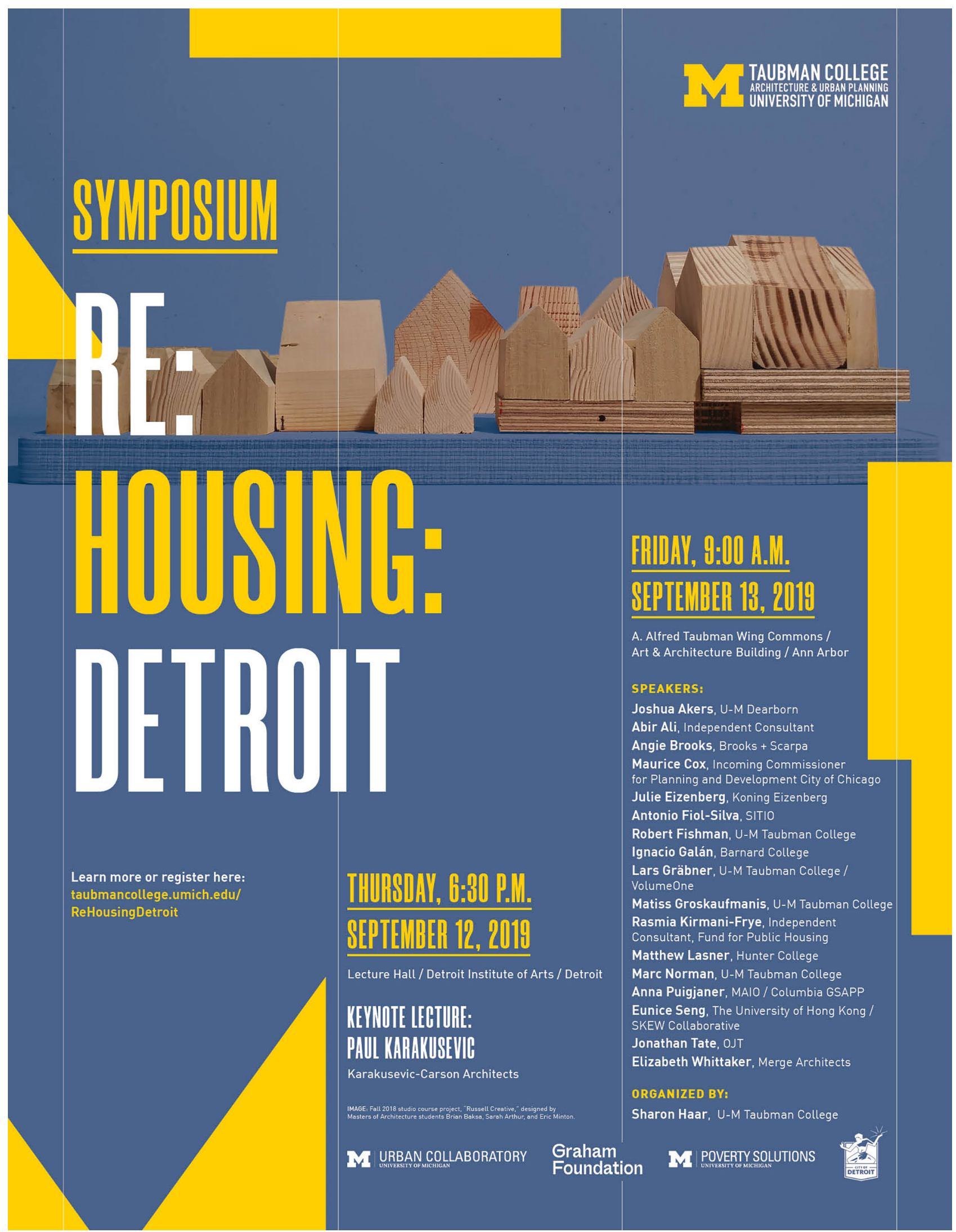

Figure 7. Re: Housing: Design Symposium, Fall 2019. (Credit: Taubman College) 
and the team was particularly interested in the design of a building envelope for maximum solar shading. The proposed program included shared amenities, from highly public at street level to widened corridors on residential floors, encouraging interaction across units designed for varying family sizes (Figure 4).

Russel Creative gave greater attention to site strategy and the organization of a live + work collective living environment organized around shared resources and spaces at both the unit and community scales. Utilizing the figure of the single-family home, it simultaneously enlarges and connects the singular units into a perimeter block that organizes a communal courtyard with select opportunities to open up to the neighborhood when desired. Ground floor commercial and neighborhood spaces allow the envisioned artist- and artisan-residents of the collective to share their work with the community (Figure 5).

\section{IMPACT}

In public lectures Cox demonstrates how student projects have influenced the final design and approach of several new developments, including one by the Detroit-based developer The Platform for a five-acre project that broke ground along the Dequindre Cut in 2018. Additionally, the studio has several externally facing components. Selected projects are exhibited in Detroit Design 139, a biennial exhibition with broad reach to Detroit audiences through workshops, panel discussions, and tours (Figure 6).

In fall 2019 the college sponsored a symposium-Re: Housing: Detroit-that brought together practitioners, academics, and policy experts from cities including Los Angeles, New York, New Orleans, and Hong Kong to contextualize the work occurring in Detroit, with particular emphasis on medium-density housing, urban development protocols, and new domestic organization. Presented to a large in-person and a streaming audience, the day-long event attracted architects, urban planners, and academics across the US (Figure 7). With a fiveyear Memorandum of Understanding in place between the university and the city, the goal is to produce a comprehensive publication that situates the student work and contemporary projects into the larger national conversation around "missing middle" density housing.

\section{ENDNOTES}

1. The studio is coordinated by Lars Gräbner and an accompanying buiding technology course is coordinated by Mick Kennedy. Since fall 2016 the studio has been taught by: Craig Borum, Claudia Wigger, Mick Kennedy, Kit McCullough, been taught by: Craig Borum, Claudia Wigger, Mick Kennedy, Kit McCullough,
James Witherspoon, Joel Schmidt, Kim Dowdell, U. Sean Vance, Kevin Adkins, Daniel Jacobs, De Peter Yi, Kasey Vliet, Christina Hansen, Kathy Velikov, and Jonathan Rule.

2. Dan Pitera, “Urban Scratches: Revealing Hidden Histories \& Instigating Future Traditions," in Detroit Collaborative Design Center, Syncopating the Urban Landscape (Detroit: University of Detroit Mercy, 2014), 4.

3. See Robert Fishman, "Detroit and the Acceleration of History," Log 37 (2016): 32-64

4. Pitera, "Urban Scratches," 4-5. 